\title{
Biological Characterization of Sesamum Phyllody Disease in Assam, India
}

\author{
Shankar Hemanta Gogoi ${ }^{1^{*}}$, M.K. Kalita ${ }^{2}$ and P.D. Nath ${ }^{1}$ \\ ${ }^{1}$ Department of Plant Pathology, College of Agriculture, AAU, Jorhat-13, Assam, India \\ ${ }^{2}$ Department of Plant Pathology, Biswanath College of Agriculture, AAU, \\ Jorhat-13, Assam, India \\ *Corresponding author
}

\begin{abstract}
A B S T R A C T
To know about the transmission behavior, biological characterization of Sesamum phyllody disease was conducted. The leafhopper Orosius albicinctus (Dist.) could transmit the disease successfully in artificial inoculation. The rate of transmission of the disease

\section{Keywords}

Sesamum Phyllody, Orosius albicinctus

(Dist.), Acquisition feeding period,

Inoculation feeding period.

Article Info

Accepted:

15 September 2017

Available Online:

10 November 2017

increased significantly as the no. of leafhopper was increased from 1 per plant $(29.47 \%)$ to 3 per plant $(84.26 \%)$. The disease transmission also increased significantly as the acquisition feeding (AFP) period increased from 3 days $(49.38 \%)$ to 5 days $(64.75 \%)$. Likewise, lowest disease transmission (16.67\%) was observed in plants with 5 days inoculation feeding period (IFP) and increased significantly in 10 IFP (100\%). The interaction effect of no. of leaf hopper/plant, acquisition feeding period and inoculation feeding period also exhibited positive and significant increase in transmission. Highest disease incidence was observed in plants inoculating with 3 no of leafhopper per plant +5 days AFP +7 and 10 days IFP and lowest in treatment with 1 leafhopper per plant +3 days AFP + 5days IFP. Similar effect was also observed in time period taken for first appearance of symptom. Lowest time period (25 days) for first appearance of symptom was taken when plants were inoculated with 3 no of leafhopper/plant +5 days AFP +7 and 10 days IFP and highest (39days) in plants inoculated with 1 leafhopper/plant +3 days AFP + 5days IFP. The Sesamum phyllody disease was successfully transmitted by graft transmission $(80 \%)$ and dodder $(90 \%)$ but it was not transmitted by seed and sap inoculation. There was no effect in germination of seeds collected from infected sesamum plants.
\end{abstract}

\section{Introduction}

Sesamum (Sesamum indicum L.) is an important ancient oilseed crop and probably the first oilseed crop used by human civilization, belongs to the family Pedaliaceae (Bedigian and Harlan, 1986). Sesamum seeds are rich source of protein (20\%), edible oil $(50 \%)$ and contains about 47 per cent oleic acid and 39 per cent linolenic acid (Shyu and Hwang, 2002). Sesamum yield is relatively low in Assam as well as in India due to low harvest index, susceptibility to diseases, seed shattering, and indeterminate growth habit (Asri, 1998). Out of these major constrains of production, Sesamum Phyllody (SP) is a very serious disease characterized by different symptoms like virescence (Plate 1), phyllody (Plate 2), yellowing, floral sterility and stem proliferation of infected plants (Bertaccini and Duduk, 2009). Phytoplasmas belongs to class molecutes are wall-less, pleomorphic, 
unculturable prokaryotes, reside in the plant phloem, feeds on the plant nutrients for survival and have small (500-1350 Kbp), AT rich genome (Doi et al., 1967; Razin et al., 1998). It has been reported to effect more than 600 different plant species. In India, the loss in yield due to sesamum phyllody was reported to be 80 to 100 percent (Sahambi, 1970; Verma and Daftari, 1976 and Kumar and Mishra, 1992). Sesamum phyllody is transmitted by leaf hopper, Orosius albicinctus Distant (Prasad and Sahambi, 1982) and Hishimonus phycitis Distant (Nabi et al., 2015).

Transmission of phytoplasma from plant to plant occurs primarily during the feeding activity of inoculative vector insects, by the vegetative propagation of infected plant material or by graft inoculation (Kirkpatrik, 1991). Vectors responsible for phytoplasma transmission in nature are insects of the order Hemiptera, primarily phloem feeding leafhoppers (Cicadellidae) and psyllids in a persistent, propagative manner (Marzachì et al., 2004). In their natural insect vectors, phytoplasmas traverse the intestinal wall, circulate in haemolymph, and multiply in tissues including salivary glands, where phytoplasma cells are incorporated into saliva injected into plants during inoculation (Weintraub and Beanland, 2006). The acquisition of multiple phytoplasmas leads to their interaction in the vector insects (Bosco and Amelio, 2010). Vector specificity varies from high, when phytoplasmas are transmitted by only one or two vectors, to extremely low, when a specific phytoplasma can be transmitted, mostly by polyphagous leafhopper species (Hogenhout et al., 2008).

Transmission of phytoplasmas through propagation material can occur and lead to their long-distance dispersal and introduction into regions where they have not previously been found (Constable, 2010). Recent reports on the detection of phytoplasma in both the seed and seedling progeny of alfalfa (Khan et al., 2002), canola (Olivier et al., 2006), corn, tomato and oilseed rape (Alberto et al., 2011) plants indicate that seed transmission in certain plant-host phytoplasma pathosystems is possible. In addition, all phytoplasmas can be transmitted experimentally by plant parasitic dodder (Cuscuta spp.) and by grafting infected plant material onto healthy plants. Though, many times sesamum phyllody suspected symptoms have been observed in Assam but not much attempt has been made to record the incidence, economic damage and the biological properties. Therefore, the present investigation was undertaken to carry out a systematic study on the biological characterization of SP disease in Assam.

\section{Materials and Methods}

\section{Insect transmission}

Healthy seeds of sesamum plants were sown in earthen pots and placed in insect free green house. Thinning was done after fifteen days of germination of seeds and four plants per pot was maintained (Plate 3). Adult Orosious albicintus Dist. leafhopper from established leafhopper colonies maintained inside insect proof cages was used as vector for the transmission test. The leafhopper was first given acquisition feeding on the Sesamum phyllody infected plant (Plate 4) for required period of time and then inoculation feeding access on the healthy sesamum plants (Plate 5). There were altogether 18 combination of number of leafhopper per plant, acquisition feeding period and inoculation feeding period with a control (no inoculation) for the transmission test which is presented in Table 1. For each treatment of insect transmission test, three pots containing four sesamum plants each were used to release the LH and another pot with four healthy sesamum plants 
was used for control where no leafhopper was released. The leafhopper in the inoculated pots was killed using insecticide after required inoculation access period was over. The killed insects were collected and stored at $-20^{\circ} \mathrm{C}$ and further analysis. Inoculated plants were continuously monitored for symptom expression. Data on percent disease incidence, time required for first appearance of the symptoms and yield parameters were recorded. The data on disease incidence and time required for first expression of symptom was analysed statistically by using Factorial CRD with three factors and data on yield parameters were analysed statistically using simple CRD (Gomez and Gomez, 1984).

\section{Mechanical transmission by grafting}

Four week old sesamum plants were used for graft inoculation using Sesamum phyllody phytoplasma (Akhtar et al., 2009) under net house conditions. For grafting, a sliced cut was made on the stem about $2-3 \mathrm{~cm}$ below the tip (Plate 6). About $13 \mathrm{~cm}$ long sesamum branch exhibiting typical phyllody symptoms was detached from an infected plant and a similar cut (as on the test plant) was made on this branch. The corresponding cut surfaces were tied together with parafilm (Plate 7). The grafted plants were kept inside humid chamber created artificially with the help of polythene bag (Plate 8) and removed after 7 days. Altogether 10 plants were grafted and the grafted plants were observed daily for symptom development.

\section{Dodder transmission}

Dodder transmission study was made according to Marcone et al., (1997). Dodder (Cuscuta campestris) strands were established on Sesamum phyllody disease-infected sesamum plants for 4 weeks. The newly developed dodder strands from diseased plants were then attached to healthy four week-old sesamum seedlings (Plate 9). The dodder bridge between the Sesamum phyllody infected plant and the inoculated plants were detached after 4 weeks and observed regularly for symptom development.

\section{Sap transmission}

For sap transmission Sesamum plant tissues with typical Sesamum phyllody disease symptom were collected and ground in $0.02 \mathrm{M}$ phosphate buffer ( $\mathrm{pH}$ 7.4) with mortar and pestle (Plate 10) and then squeeze through very fine muslin cloth as described by Akhtar et al., (2009). A pinch of Carborandum powder was sprinkled over the leaves to be inoculated to cause injury in the leaf tissues for the penetration of the Phytoplasma (Plate 11). Two young leaves from 4 week old healthy sesamum plants were mechanically inoculated with the freshly extracted sap using cotton pads. Inoculated leaves were rinsed with a gentle stream of water immediately after inoculation to remove superfluous inoculums and place in insect proof cages. Altogether 10 plants were used for sap inoculation and the inoculated plants were observed regularly for symptom development.

\section{Seed transmission}

Matured seeds from Sesamum phyllody infected and healthy sesamum plants were collected and stored in the laboratory. One hundred seeds each from diseased and healthy sesamum plants were raised on earthen pots inside insect proof cages. Germination percentage, number of plants showing symptoms and time taken for symptom development was observed until maturity.

\section{Results and Discussion}

\section{Insect transmission}

Sesamum phyllody phytoplasma was successfully transmitted from infected 
sesamum plants to healthy sesamum plants (Plate12) by the leafhopper vector Orosius albicinctus Dist. (Plate 13) under net house condition. Successful transmission of Sesamum phyllody disease with the same vector was also reported (Akhtar et al., 2009; Pathak et al., 2013 and Cengiz et al., 2014). The percent disease transmission was significantly influenced by the number of leafhopper released per plant, acquisition feeding period and inoculation feeding period of the leafhopper vector (Table 2). Highest disease transmission (84.26\%) was observed in plants inoculated with 3 leafhopper/plant. This was followed by 57.41 percent and 29.47 per cent in plants inoculated with 2 leafhopper/plant and 1 leafhopper per plant respectively. Likewise, the disease transmission was also influenced by the duration of acquisition feeding period. Lowest disease transmission (49.38\%) was observed in plants inoculated with leafhopper allowing 3 days acquisition feeding access which increased significantly to 64.75 per cent when inoculated with leafhopper allowing 5 days acquisition feeding period. The Inoculation feeding period also exhibited influence in the rate of disease transmission. The disease transmission increased with the increase in inoculation feeding period of the leafhopper. The disease transmission was observed to be $52.16,57.87$ and 61.11 per cent in plants in which leafhopper were given inoculation feeding period of 5,7 and 10 days respectively. There was no significant difference in disease transmission in plants inoculated with leafhopper allowing 5 days and 7 days inoculation feeding and 7 days and 10 days inoculation feeding period. The percent disease transmission differed significantly between 5 days and 10 days inoculation feeding period. There was significant increase in the rate of disease transmission as the number of leafhopper was increased from 1 to 3 per plant. This may be due to deposition of more inoculums in the sesamum plant where 3 leafhopper per plant was released as compared to 1 or 2 leafhopper per plant. The positive correlation between higher disease incidences with increased number of vectors was also reported by Jayashree et al., (1999) in Pumpkin Yellow Mosaic virus disease as observed in the present investigation.

The interaction between acquisition feeding period and number of insects per plant was seen to influence the rate of disease transmission. Highest disease transmission $(97.22 \%)$ was observed in treatments where leafhoppers were given 5 days acquisition feeding and 3 leafhoppers were released per plant. This treatment differed significantly with all other treatments. Lowest disease transmission $(23.15 \%)$ was observed in treatments where leafhopper was given 3 days acquisition feeding and 1 leafhopper per plant was released.

The interaction between inoculation feeding period and number of insects per plant also influence the rate of disease transmission. Highest disease transmission $(87.50 \%)$ was observed in treatments where leafhoppers were given 10 days acquisition feeding and 3 leafhoppers were released per plant. Lowest disease transmission (23.15\%) was observed in treatments where leafhoppers were given 5 days inoculation feeding and 1 leafhopper per plant was released. There was no significant difference in the disease transmission when same number of leafhopper per plant was used but the rate of disease transmission varied significantly when number of leafhopper was increased from 1 to 3 irrespective of inoculation feeding period.

Among the three combinations of treatments, highest disease transmission (100\%) was observed in plants inoculated with 3 leafhopper/plant +5 days acquisition feeding period +7 days inoculation feeding period 
and 3 leafhopper/plant +5 days acquisition feeding period +10 days inoculation feeding period. Lowest disease transmission (16.67\%) was observed in plants inoculated with 1 leafhopper/plant +3 days acquisition feeding period +5 days inoculation feeding period.

The interaction between the number of leafhopper per plant and acquisition feeding period, number of leafhopper per plant and inoculation feeding period, acquisition feeding period and inoculation feeding period and among number of leafhopper per plant, acquisition feeding period, inoculation feeding period had significantly influenced the transmission of the disease. The interaction effect of the factors (i.e. number of leafhopper released per plant, acquisition feeding period and inoculation feeding period) was increased corresponding to the increase of the individual factors. The phytoplasma for insect transmission has a latent period (Webb et al., 1999 and Bertaccini and Duduk, 2009). Again, the percent transmission of the disease increased with the increased number of vectors, acquisition feeding period and inoculation feeding period (Jayashree et al., 1999). The facts of all these earlier report might have contributed for more percent of disease incidence observed in the present study with more number of leafhopper vector per plant, increased acquisition feeding period and increased inoculation feeding period.

\section{Effect on duration for first appearance of symptoms}

The leafhopper Orosius albicinctus Dist. successfully transmitted Sesamum phyllody disease from infected plant to healthy sesamum plant. It was observed that the period for first appearance of disease symptom was significantly influenced by the number of leafhopper released per plant, acquisition feeding period and inoculation feeding period of the leafhopper vector (Table 3 ). There was significant reduction in the time period required for first appearance of disease symptoms as the number of leafhopper was increased from 1 to 3 per plant. Highest (36.39 days) was required in plants inoculated with 1 insects/plant. This was followed by 32.17 days and 27.33 days in plants inoculated with 2 insect per plant and 3 insect per plant respectively. This may be due to the fact that more numbers leafhopper per plant deposited of more amount of inoculums in the healthy sesamum plant as compared to less number of leafhopper per plant. Jayashree et $a l$. , (1999) reported that the days required for the symptom expression of Pumpkin yellow vein mosaic virus infection became progressively less as the numbers of whiteflies used for inoculating the test plants were gradually increased from one to twenty.

The time period required for first appearance of symptoms of Sesamum phyllody disease was decreased with the increase in the acquisition feeding period and inoculation feeding period of the leaf hopper vector Orosius albicinctus Dist. Lowest (30.92 days) was observed in plants inoculated with leafhopper allowing 5 days acquisition feeding access which increased significantly to 32.99 days when inoculated with leafhopper allowing 3 days acquisition feeding period. The appearance of symptom (days) decreased with the increase in inoculation feeding access of the insects. The symptom development was observed to be 33.22 days, 31.73 days and 30.95 days in plants in which leafhopper were given inoculation access period of 5 days, 7days and 10 days respectively. There was no significant difference in symptom in plants inoculated with leafhopper allowing 5 days and 7 days inoculation feeding and 7 days and 10 days inoculation feeding period. The symptom development differed significantly between 5 days and 10 days inoculation feeding period. 


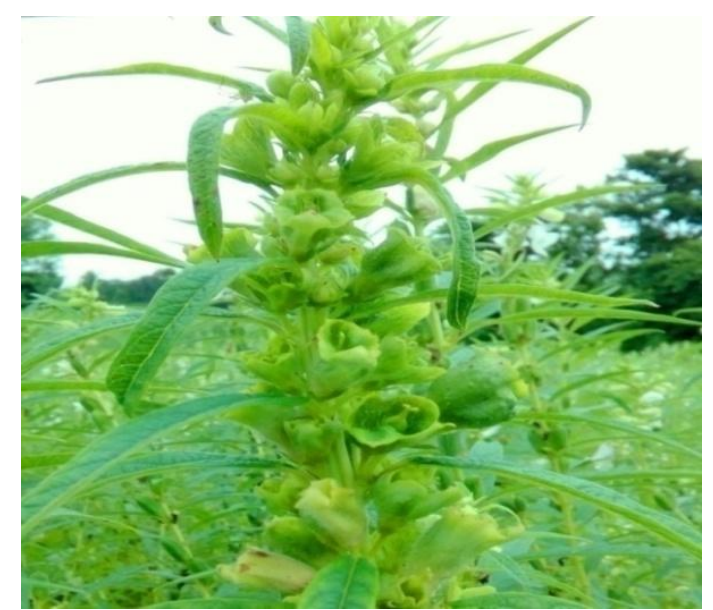

Plate.1 Floral virescence

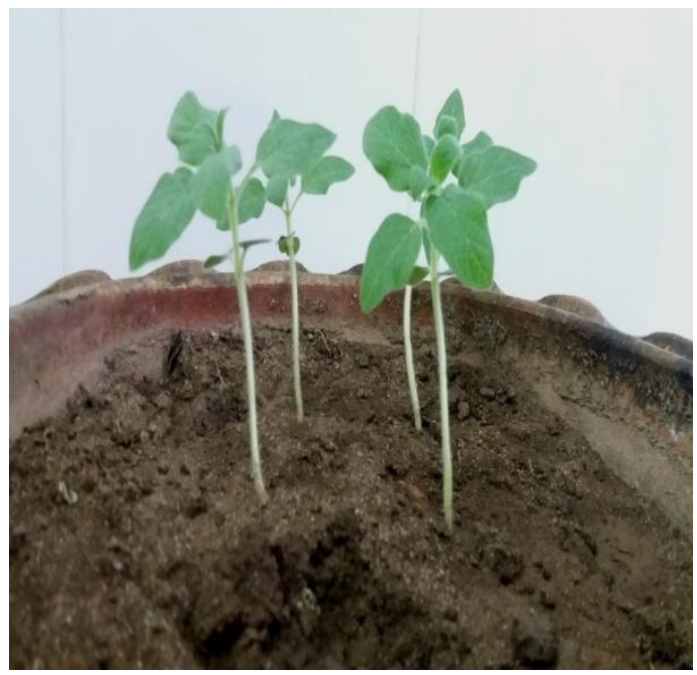

Plate.3 Raising of Sesamum plants

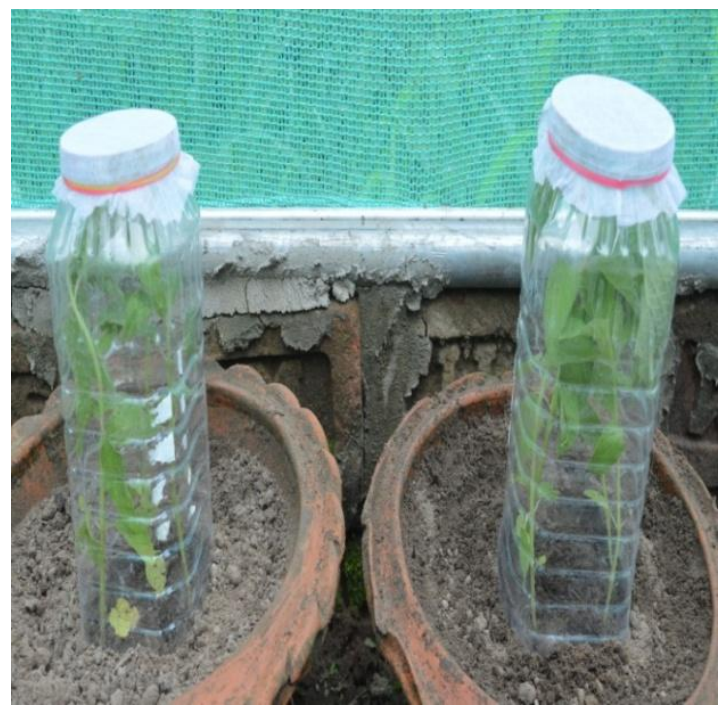

Plate.5 Inoculation feeding of Leafhopper

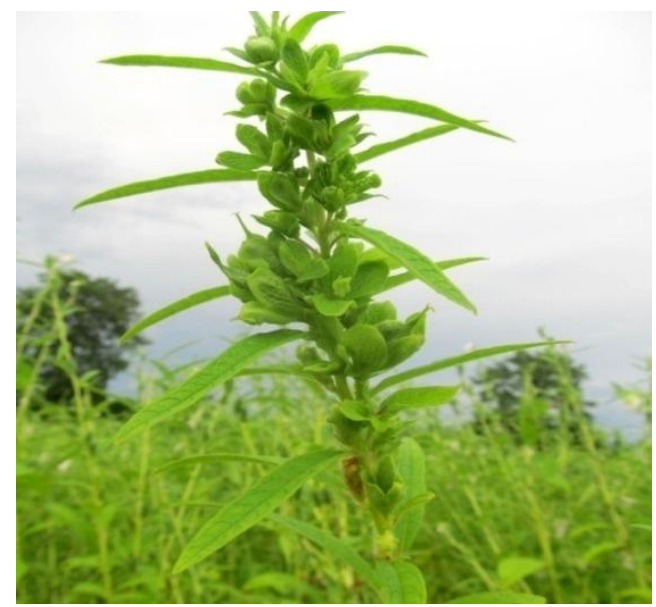

Plate.2 Phyllody

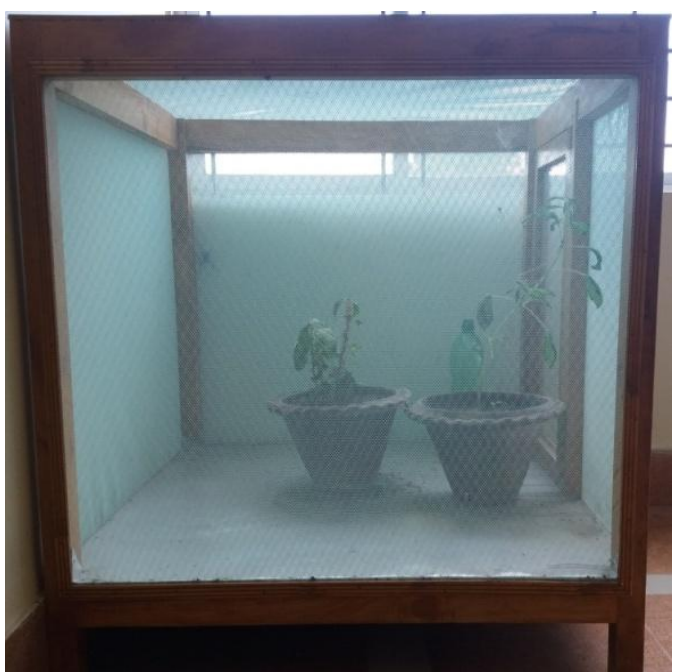

Plate.4 Acquisition feeding of leafhopper

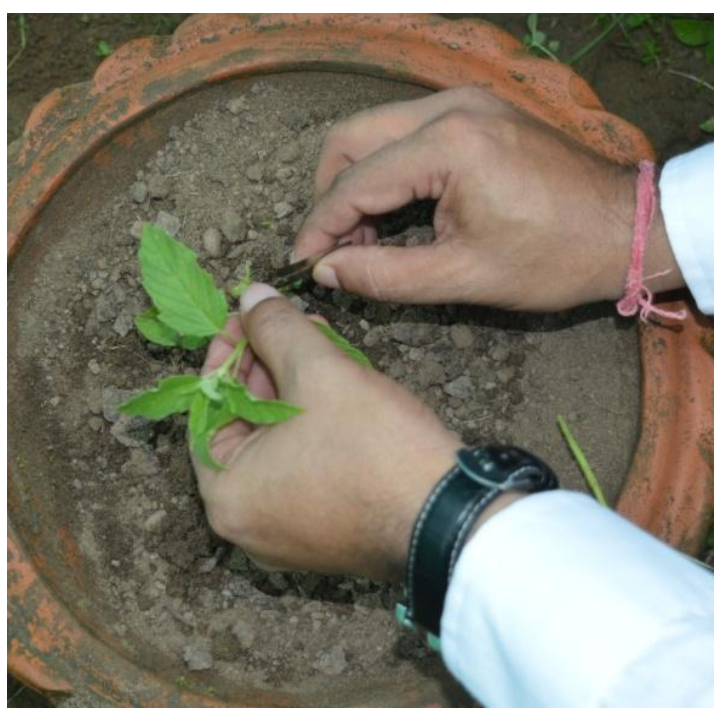

Plate.6 Slice cut for grafting 


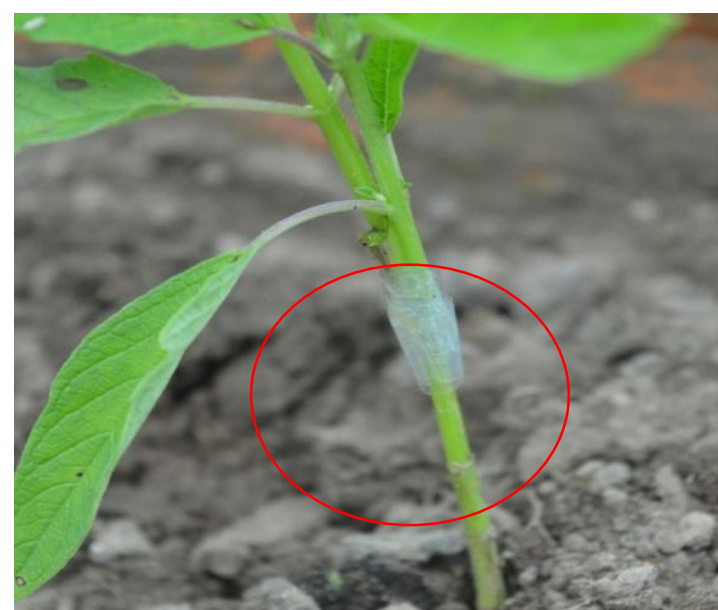

Plate.7 Para film wrapping

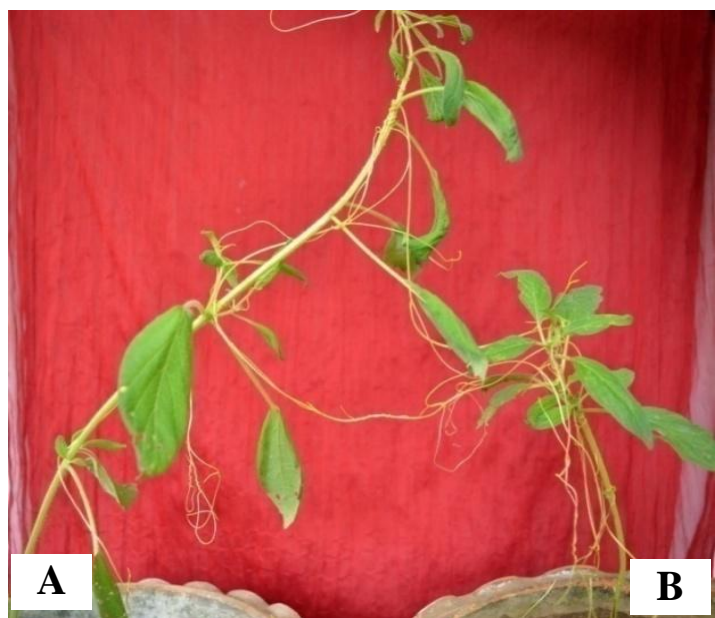

Plate.9 Dodder transmission (A) Infected plant (B) Healthy plant

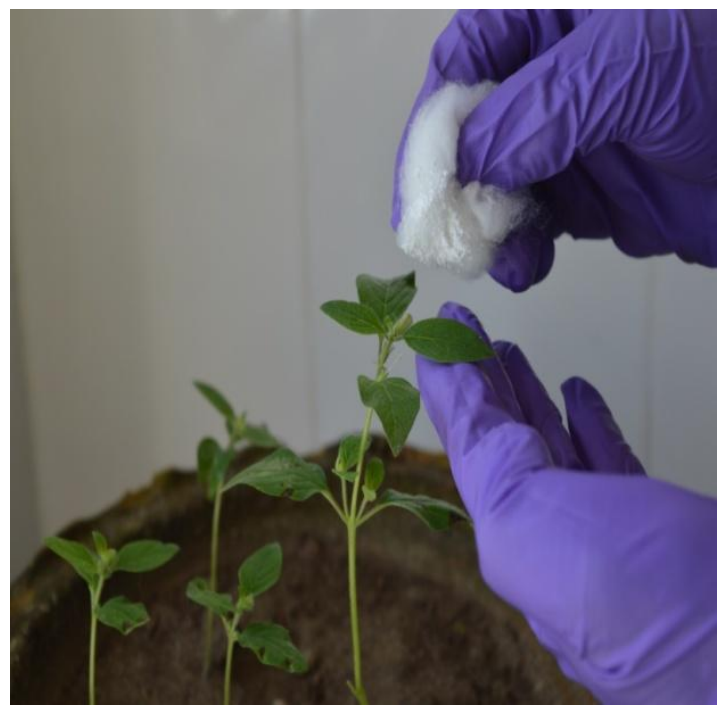

Plate.11 Plants just before sap inoculation

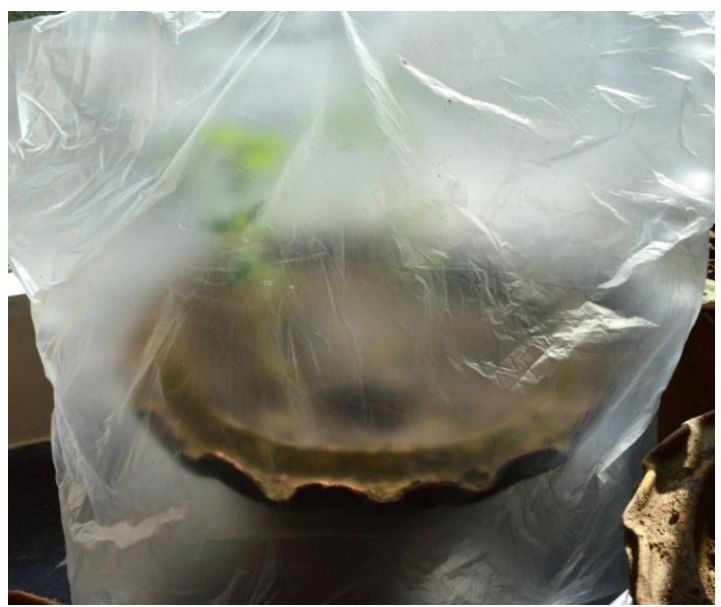

Plate.8 Grafted plant inside humid chamber

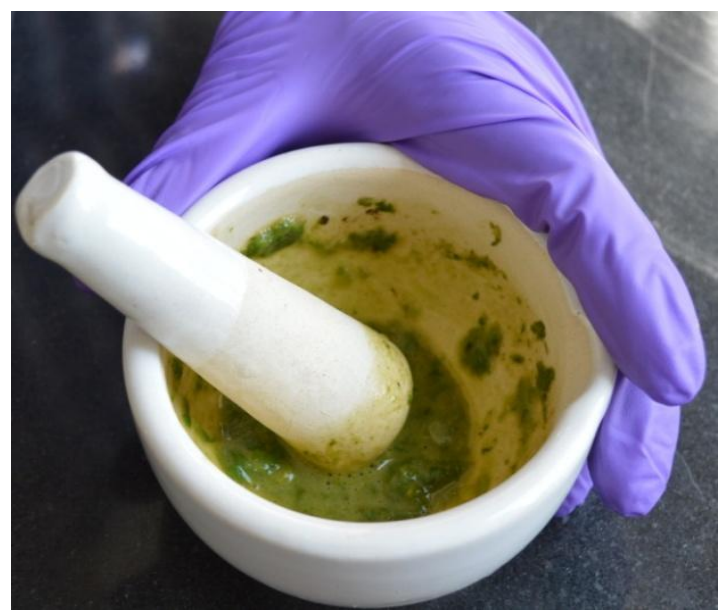

Plate.10 Grinding of diseased plant tissue

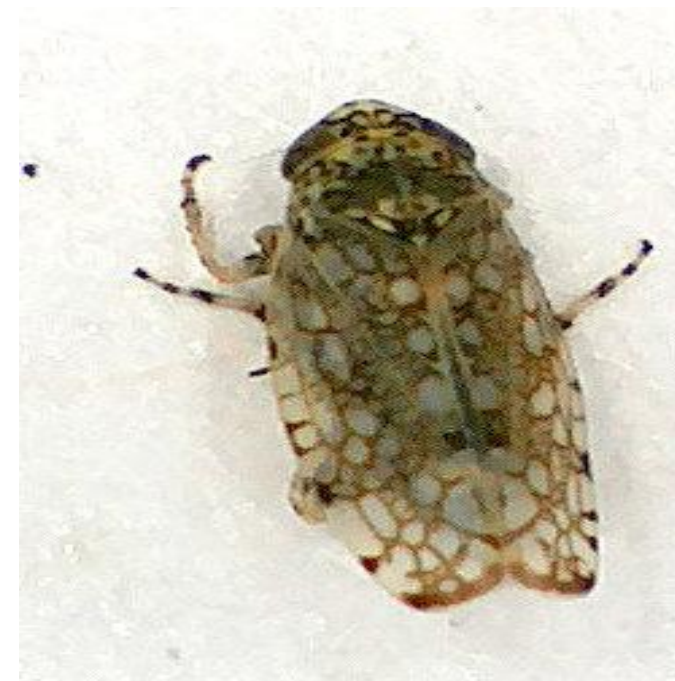

Plate.12 Orosius albicinctus Dist. 


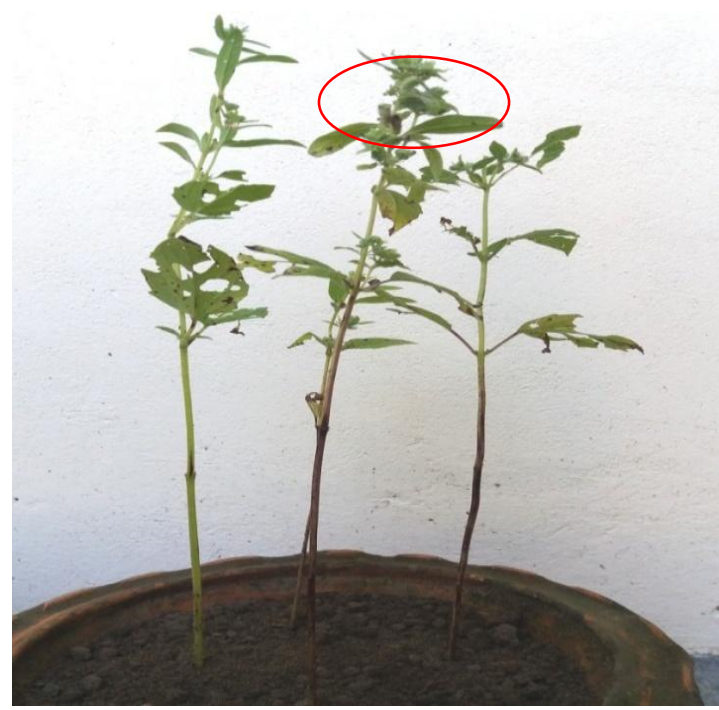

Plate.13 Symptom in insect transmitted Plants

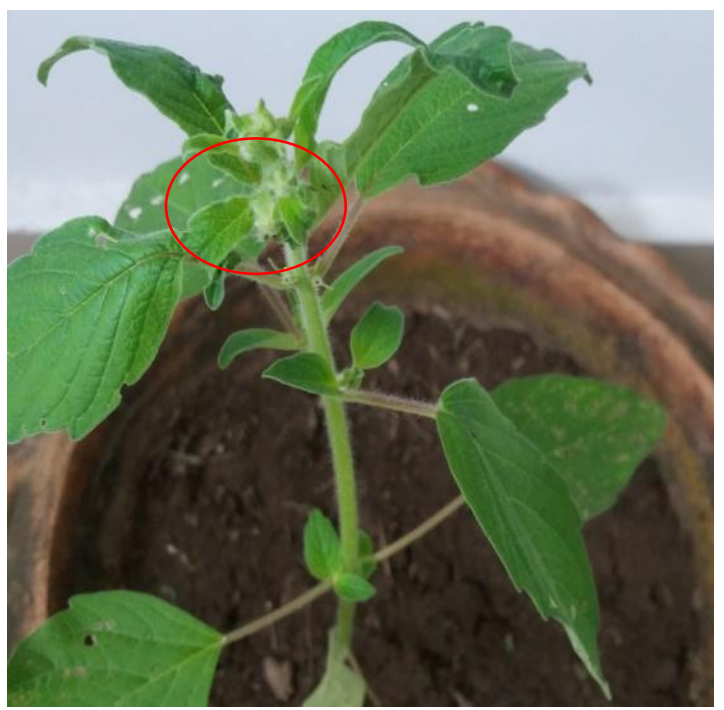

Plate.14 Symptom in graft transmitted plant

Plate.15 PCR analysis of graft transmitted plants

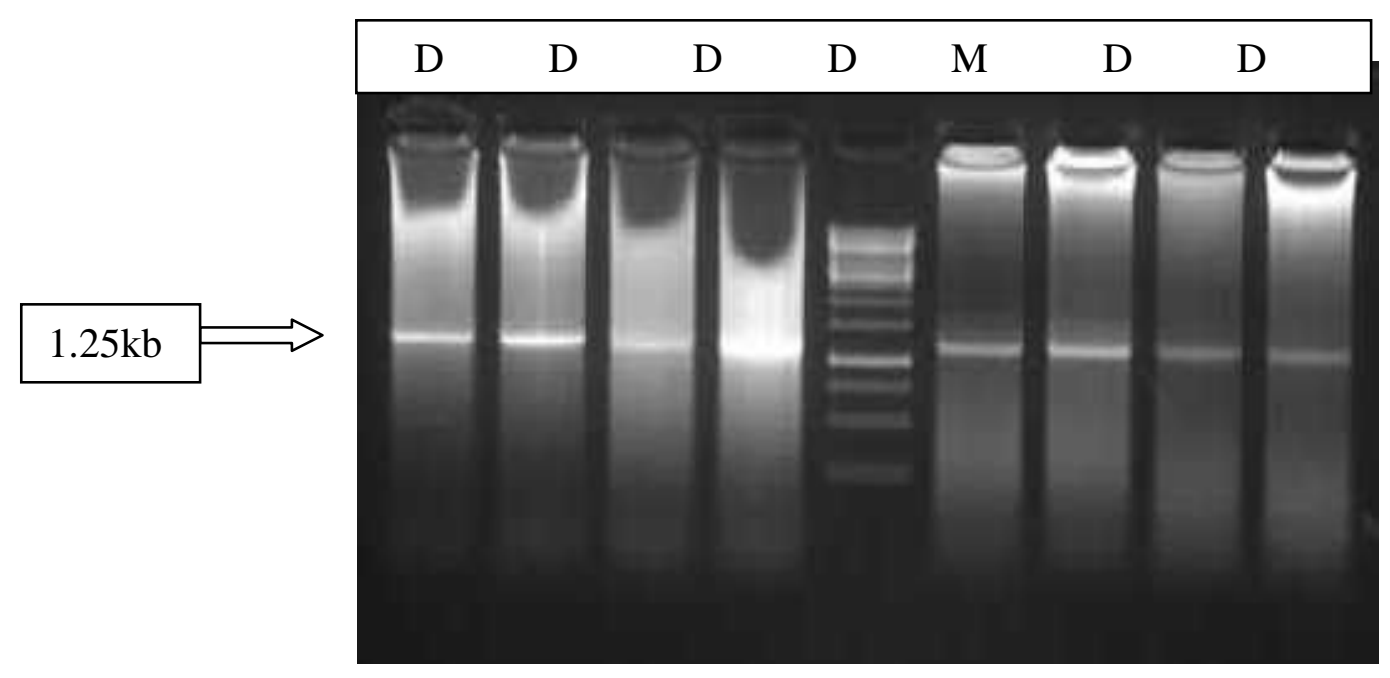

Plate.16 Symptom in dodder transmitted plant

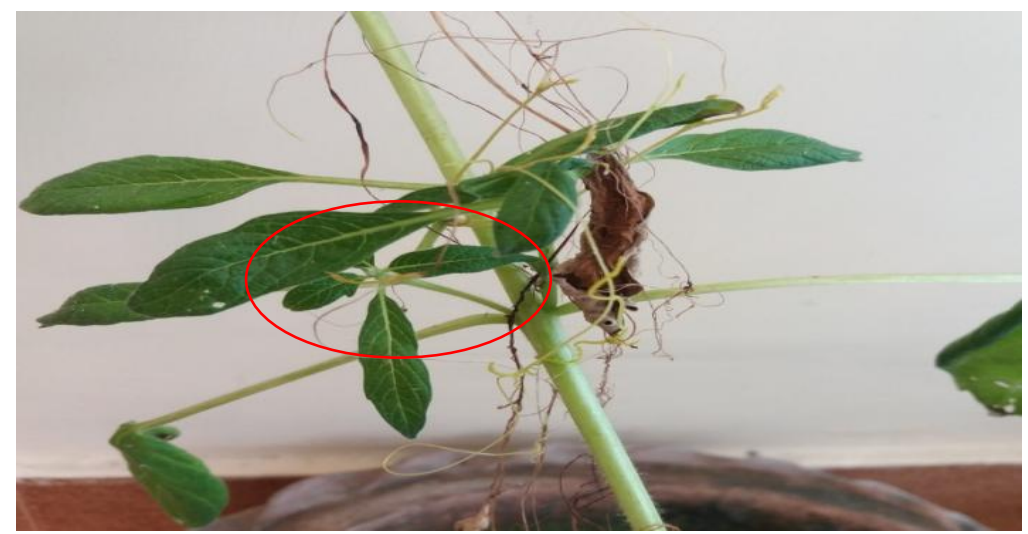


Table.1 Treatments for conducting insect transmission of sesamum phyllody disease

\begin{tabular}{|c|c|}
\hline Treatment No. & Treatments \\
\hline$T_{1}$ & 1 insect/plant + 3 DAF + 5 DIF \\
\hline$T_{2}$ & 2 insect/plant + 3 DAF + 5 DIF \\
\hline$T_{3}$ & 3 insect/plant + 3 DAF + 5 DIF \\
\hline$T_{4}$ & 1 insect/plant + 3 DAF + 7 DIF \\
\hline$T_{5}$ & 2 insect/plant + 3 DAF + 7 DIAF \\
\hline$T_{6}$ & 3 insect/plant + 3 DAF + 7 DIF \\
\hline$T_{7}$ & 1 insect/plant + 3 DAF + 10 DIF \\
\hline$T_{8}$ & 2 insect/plant + 3 DAF + 10 DIF \\
\hline$T_{9}$ & 3 insect/plant + 3 DAF + 10 DIF \\
\hline$T_{10}$ & 1 insect/plant + 5 DAF + 5 DIF \\
\hline$T_{11}$ & 2 insect /plant + 5 DAF + 5 DIF \\
\hline$T_{12}$ & 3 insect/plant + 5 DAF + 5 DIF \\
\hline$T_{13}$ & 1 insect/plant + 5 DAF + 7 DIF \\
\hline$T_{14}$ & 2 insect/plant + 5 DAF + 7 DIF \\
\hline$T_{15}$ & 3 insect/plant + 5 DAF + 7 DIF \\
\hline$T_{16}$ & 1 insect/plant + 5 DAF + 10 DIF \\
\hline$T_{17}$ & 2 insect/plant + 5 DAF + 10 DIF \\
\hline$T_{18}$ & 3 insect/plant + 5 DAF + 10 DIF \\
\hline$T_{19}$ & No inoculation $(\mathrm{Control})$ \\
\hline
\end{tabular}

* DAF- Days of Acquisition Feeding

* DIF- Days of Inoculation Feeding

Table.2 Effect of Leaf hoppers per plant, acquisition and inoculation feeding period and their interactions in the incidence of Sesamum phyllody disease

\begin{tabular}{|c|c|c|c|c|c|c|c|c|c|c|c|c|}
\hline \multirow{3}{*}{$\begin{array}{c}\text { No of } \\
\text { insect } \\
\text { per } \\
\text { plant }\end{array}$} & \multicolumn{12}{|c|}{ Disease incidence $(\%)$} \\
\hline & \multicolumn{3}{|c|}{3 DAF* } & \multicolumn{4}{|c|}{5 DAF } & \multicolumn{2}{|c|}{ DAF $x$ No. of insect } & \multicolumn{3}{|c|}{ DIF $x$ No. of insect } \\
\hline & $\begin{array}{c}\mathbf{5} \\
\text { DIF }^{* *}\end{array}$ & $\begin{array}{c}7 \\
\text { DIF }\end{array}$ & $\begin{array}{c}10 \\
\text { DIF }\end{array}$ & $\begin{array}{c}5 \\
\text { DIF }\end{array}$ & 7 DIF & \begin{tabular}{|c|}
10 \\
DIF
\end{tabular} & Mean & 3 DAF & 5 DAF & $\begin{array}{c}5 \\
\text { DIF }\end{array}$ & $\begin{array}{c}7 \\
\text { DIF }\end{array}$ & $\begin{array}{c}10 \\
\text { DIF }\end{array}$ \\
\hline 1 & 16.67 & 25.00 & 27.78 & 29.62 & 36.11 & 41.66 & 29.47 & 23.15 & 35.80 & 23.15 & 30.56 & 34.72 \\
\hline 2 & 50.00 & 52.77 & 58.33 & 58.33 & 61.11 & 63.89 & 57.41 & 53.70 & 61.24 & 54.15 & 56.95 & 61.11 \\
\hline 3 & 66.67 & 72.22 & 75.00 & 91.67 & 100.00 & 100.00 & 84.26 & 71.30 & 97.22 & 79.17 & 86.11 & 87.50 \\
\hline Mean & 44.45 & 50.00 & 53.70 & 59.87 & 65.74 & 68.52 & & 49.38 & 64.75 & 52.16 & 57.87 & 61.11 \\
\hline Control & 0.00 & 0.00 & 0.00 & 0.00 & 0.00 & 0.00 & & 0.00 & 0.00 & 0.00 & 0.00 & 0.00 \\
\hline
\end{tabular}

\begin{tabular}{|l|c|c|c|c|c|}
\hline \multicolumn{1}{|c|}{ Treatments } & $\begin{array}{c}\text { SEm } \\
\mathbf{\pm}\end{array}$ & $\begin{array}{c}\text { CD } \\
(\mathbf{p = 0 . 0 5})\end{array}$ & Treatments & $\begin{array}{c}\text { SEm } \\
\mathbf{\pm}\end{array}$ & $\begin{array}{c}\text { CD } \\
(\mathbf{p = 0 . 0 5})\end{array}$ \\
\hline No. of Insect & 3.92 & 6.54 & Acquisition period x No. of insect & 5.54 & 9.25 \\
\hline Acquisition period & 3.20 & 5.34 & Inoculation period x No. of insect & 5.56 & 9.27 \\
\hline Inoculation period & 3.94 & 6.56 & Acquisition period x Inoculation period & 6.79 & 11.33 \\
\hline \multicolumn{2}{|r|}{ Acquisition period x Inoculation period x No. of insect } & 9.6 & 16.03 \\
\hline
\end{tabular}

*DAF- Days of Acquisition Feeding

**DIF- Days of Inoculation Feeding 
Table.3 Effect of leaf hoppers per plant, acquisition and inoculation feeding period and their interactions in the time period for first appearance of symptom

\begin{tabular}{|c|c|c|c|c|c|c|c|c|c|c|c|c|}
\hline \multirow{3}{*}{$\begin{array}{c}\text { No of } \\
\text { insect } \\
\text { per } \\
\text { plant }\end{array}$} & \multicolumn{12}{|c|}{ Time period for first appearance of symptom (No. of days) } \\
\hline & \multicolumn{3}{|c|}{3 DAF* } & \multicolumn{4}{|c|}{5 DAF } & \multicolumn{2}{|c|}{ DAF $x$ No. of insect } & \multicolumn{3}{|c|}{ DIF $x$ No. of insect } \\
\hline & $\begin{array}{c}\mathbf{5} \\
\text { DIF }^{* *}\end{array}$ & 7 DIF & $\begin{array}{c}10 \\
\text { DIF }\end{array}$ & 5 DIF & 7 DIF & $\begin{array}{c}10 \\
\text { DIF }\end{array}$ & Mean & 3 DIF & 5 DIF & 5 DIF & 7 DIF & $\begin{array}{c}10 \\
\text { DIF }\end{array}$ \\
\hline 1 & 39.00 & 37.67 & 35.00 & 37.00 & 35.00 & 34.67 & 36.39 & 37.22 & 35.56 & 38.00 & 36.34 & 34.84 \\
\hline 2 & 33.67 & 32.00 & 31.67 & 33.67 & 31.67 & 30.33 & 32.17 & 32.44 & 31.89 & 33.67 & 31.84 & 31.00 \\
\hline 3 & 30.00 & 29.00 & 29.00 & 26.00 & 25.00 & 25.00 & 27.33 & 29.33 & 25.33 & 28.00 & 27.00 & 27.00 \\
\hline Mean & 34.23 & 32.89 & 31.89 & 32.22 & 30.56 & 30.00 & & 32.99 & 30.92 & 33.22 & 31.73 & 30.95 \\
\hline Control & 0.00 & 0.00 & 0.00 & 0.00 & 0.00 & 0.00 & & 0.00 & 0.00 & 0.00 & 0.00 & 0.00 \\
\hline
\end{tabular}

\begin{tabular}{|c|c|c|c|c|c|}
\hline Treatments & $\begin{array}{c}\text { SEm } \\
\pm \\
\end{array}$ & $\begin{array}{c}\text { CD } \\
(p=0.05)\end{array}$ & Treatments & $\begin{array}{c}\text { SEm } \\
\pm\end{array}$ & $\begin{array}{c}\text { CD } \\
(p=0.05)\end{array}$ \\
\hline No. of Insect & 0.43 & 0.73 & No. of insect $\mathrm{x}$ Acquisition period & 0.62 & 1.03 \\
\hline Acquisition period & 0.35 & 0.59 & No. of insect $x$ Inoculation period & 0.76 & 1.27 \\
\hline Inoculation period & 0.45 & 0.75 & Acquisition period $\mathrm{x}$ Inoculation period & 0.64 & 1.05 \\
\hline \multicolumn{4}{|c|}{ Acquisition period $\mathrm{x}$ Inoculation period $\mathrm{x}$ No. of insect } & 1.07 & 1.79 \\
\hline
\end{tabular}

*DAF- Days of Acquisition Feeding

***DIF- Days of Inoculation Feeding

Table.4 Transmission of sesamum phyllody disease by graft transmission method

\begin{tabular}{|c|c|c|c|c|c|}
\hline $\begin{array}{c}\text { No of } \\
\text { plant } \\
\text { grafted }\end{array}$ & $\begin{array}{c}\text { Symptom } \\
\text { observed after } \\
\text { grafting (days) }\end{array}$ & Symptom & $\begin{array}{c}\text { Plant showing } \\
\text { symptom/ Total } \\
\text { number of plants }\end{array}$ & $\begin{array}{c}\text { PCR positive } \\
\text { plants/Total number } \\
\text { of test plant }\end{array}$ & $\begin{array}{c}\text { Percent } \\
\text { transmission } \\
(\%)\end{array}$ \\
\hline 10 & $30-40$ & $\begin{array}{c}\text { Yellowing of } \\
\text { leaves, Phyllody }\end{array}$ & $6 / 10$ & $8 / 10$ & 80 \\
\hline
\end{tabular}

Table.5 Transmission of sesamum phyllody disease by dodder transmission method

\begin{tabular}{|c|c|c|c|c|c|}
\hline $\begin{array}{c}\text { No of } \\
\text { plant } \\
\text { inoculated }\end{array}$ & $\begin{array}{c}\text { Symptom } \\
\text { observed } \\
\text { after } \\
\text { grafting(days) }\end{array}$ & Symptom & $\begin{array}{c}\text { Plant showing } \\
\text { symptom/ Total } \\
\text { number of } \\
\text { plants }\end{array}$ & $\begin{array}{c}\text { PCR positive } \\
\text { plants/Total } \\
\text { number of test } \\
\text { plant }\end{array}$ & $\begin{array}{c}\text { Percent } \\
\text { transmission } \\
(\%)\end{array}$ \\
\hline 10 & $35-45$ & $\begin{array}{c}\text { Yellowing of } \\
\text { leaves, Phyllody, } \\
\text { Floral virescence }\end{array}$ & $7 / 10$ & $9 / 10$ & 90 \\
\hline
\end{tabular}

Table.6 Germination percentage of sesamum seed

\begin{tabular}{|c|c|c|c|c|}
\hline \multicolumn{2}{|c|}{ No of seed taken } & Seed germinated & Germination percentage & Symptom observed \\
\hline Healthy & 100 & 80 & 80 & - \\
\hline Diseased & 100 & 78 & 78 & - \\
\hline
\end{tabular}


More the acquisition feeding period and inoculation feeding period lesser was time period required for first appearance of symptoms of the disease. Jayashree et al., (1999) observed that as the acquisition and inoculation feeding period was increased there was higher percentage of Pumpkin yellow vein mosaic virus infected plants, and the days required for symptom expression became less. Similar observations were also made by Rashid et al., (2008) in case of Tomato Yellow Leaf Curl Virus.

The interaction between the number of leafhopper per plant and acquisition feeding period, number of leafhopper per plant and inoculation feeding period, acquisition feeding period and inoculation feeding period and among number of leafhopper per plant, acquisition feeding period, inoculation feeding period had significantly influenced the time period required for first appearance of disease symptoms. Highest percent of disease transmission $(68.52 \%)$ was observed in plants inoculated with leafhopper giving 5 days acquisition feeding and 10 days inoculation feeding period.

The lowest disease transmission (44.45\%) was observed in plants inoculated with leafhopper giving 3 days acquisition feeding and 5 days inoculation feeding period and also differed significantly. Among the three combinations of treatments, lowest time period (25 days) for symptom expression was observed in plants inoculated with 3 leafhopper/plant +5 days acquisition feeding period +7 days inoculation feeding period and also in plants inoculated with 3 leafhopper/plant +5 days acquisition feeding period +10 days inoculation feeding period. Highest time period (39 days) for first appearance of symptom was observed in plants inoculated with 1 leafhopper/plant +3 days acquisition feeding period +5 days inoculation feeding period.
The interaction effect of the factors (i.e. number of leafhopper released per plant, acquisition feeding period and inoculation feeding period) was increased with the increase of the individual factors and there was corresponding decrease in the time period required for first appearance of disease symptoms.

The Phytoplasmas enter the body of the insect through the stylet, move through the intestine, and are then absorbed into the haemolymph. From haemolymph they proceed to colonize the salivary glands, reaching an infectious titer and after that only it can transmit the phytoplasma to the plant. To complete this process a time period of up to three weeks is required (Carraro et al., 2001; Christensen et al., 2005). This might be the cause of the findings of the present study where reduced time period required for symptom development was observed in case of increased number of vector per plant, increased acquisition feeding period and increased inoculation feeding period of the leafhopper vectors.

\section{Graft transmission}

In the present study Sesamum phyllody disease was successfully transmitted from infected plant to the healthy sesamum plant by grafting. Symptom started appearing from $30^{\text {th }}$ day of grafting and continued up to $40^{\text {th }}$ day (Plate 14).

Out of 10 grafted plants 6 plants showed distinct Sesamum phyllody symptoms. When the grafted plants were analysed by PCR assay 8 out of the 10 grafted plants showed positive result (Plate 15). This result indicated that Sesamum phyllody was transmitted to 80 per cent of the graft transmitted plants (Table 4). Similar observations were also reported by Salehi et al., (1992), Akhtar et al., (2009) and Pathak et al., (2012). The Phytoplasmas move 
within plants through the phloem from source to sink and they are able to pass through sieve tube elements in phloem tissues (Christensen et al., 2004). Due to this nature probably they are transmitted in the process of grafting. Jarausch et al., (1999) observed successful transmission of European stone fruit yellows (ESFY) phytoplasma by graft transmission. Kamińska and Korbin (1999) reported graft transmission of phytoplasma affecting Lily plant. Likewise, Salehi et al., (2009) could successfully transmitted Sunflower phyllody phytoplasma by graft transmission.

\section{Dodder transmission}

Dodder (Cuscuta campestris) successfully transmitted the Sesamum phyllody phytoplasma from infected plant to healthy sesamum plants under net house conditions (Plate 16). The dodder transmitted sesamum plants took 35 to 45 days to express the symptoms after transmission (Table 5).

Out of 10 plants used for dodder transmission, 7 plant exhibited typical phyllody symptom followed by yellowing of leaves and floral virescence. In the PCR assay 9 plants out of 10 plants used for dodder transmission showed positive result indicating 90 per cent transmission by dodder.

This indicated that dodder can be a effective means in natural transmission of the disease in the field. Earlier, Abraham et al., (1977) reported that dodder (Cuscuta campestris) played role for transmission, donor as well as reservoir of sesamum phytoplasma.

Similarly many other workers could also successfully transmit the disease from infected plant to healthy plant with the help of dodder (Salehi and Izadpanah, 1992; Akhtar et al., 2009 and Pathak et al., 2012).Marcone et al., (1997) reported successful dodder transmission of alder yellows phytoplasma to the experimental host Catharanthus roseus (periwinkle). Similarly, Salehi et al., (2009) could successfully transmitted Sunflower phyllody phytoplasma by dodder.

\section{Seed and sap transmission of Sesamum phyllody phytoplasma}

In the present investigation, the Sesamum phyllody phytoplasma could not be transmitted by seed or sap inoculation method (Table 6). The plants raised from seed collected from Sesamum phyllody infected plant did not show any symptoms.

Likewise, plants inoculated with sap extracted from Sesamum phyllody infected plants were also remained free from infection. Out of the ten plants inoculated with sap, no symptom was observed in the plants. The present finding is in conformity with the earlier reports (Flectcher et al., 1998; Akhtar et al., 2009 and Pathak et al., 2012).

\section{Acknowledgements}

The authors acknowledge the help received from Dr. Sahidur Rahman, Senior Scientist, Department of Entomology, Assam Agricultural Univrsity, Jorhat during the transmission studies.

\section{References}

Abraham, E.V., Natarajan, K. and Murugaesan, M. 1977. Damage by pests and phyllody to Sesamum indicum in relation to time of sowing. Madras Agril. J. 64: 298-301.

Akhtar, K.P., Sarwar, G., Dickinson, M., Ahmad, M., Haq, M.A., Hameed, S. and Iqbal, M.J. 2009. Sesame phyllody disease: its symptomatology, etiology, and transmission in Pakistan. Turk. J. Agric. For. 33: 477-486.

Alberto C., Samanta P., Nicoletta C., Dimitrijka S., Nicola M. 2011. Molecular evidence of phytoplasmas in winter oilseed rape, tomato and corn seedlings. Bulletin of 
Insectology, $64: 157-158$

Ashri, A. 1998. Sesame breeding. Plant Breed. Rev. 16: 179-228.

Bedigian, D. and Harlan, J.R. 1986. Evidence for cultivation of sesame in the ancient world. Econo. Bot. J. 40: 137-154.

Bertaccini, A. and Duduk, B. 2009. Phytoplasma and phytoplasma diseases: a review of recent research. Phytopath. Mediter. 48: 355-378.

Bosco D., D' Amelio R. 2010 Transmission specificity and competition of multiple phytoplasmas in the insect vector. In: Weintraub, P. G., and Jones, P. (eds). Phytoplasmas Genomes, Plant Hosts and Vectors. CAB International, UK. Pp.: 293308

Carraro, L., Loi, N. and Ermacora, P. 2001. Transmission characteristics of the European stone fruit yellows phytoplasma and its vector Cacopsylla pruni. European J. Plant Pathol. 107: 695-700.

Cenzig, I., Mursel, C., Engin, Y., Rustem, U., Seymus, F., Cengiz, T. and Bulent, U. 2014. Molecular identification, characterization and transmission of phytoplasmas associated with sesame phyllody in Turkey. European J. Plant Pathol. 139(1): 217.

Christensen, N., Axelsen, K., Nicolaisen, M. and Schulz, A. 2005. Phytoplasmas and their interactions with their hosts. Trends in Plant Sci. 10(11): 526-535.

Christensen, N.M., Nicolaisen, M., Hansen, M. and Schultz, A. 2004. Distribution of phytoplasmas in infected plants as revealed by real time PCR and bioimaging. Mol. Plant Microbe Inter. 17: 1175-1184.

Constable F.E. 2010 Phytoplasma epidemiology: grapevines as a model. In: Weintraub, P. G., and Jones, P. (eds). Phytoplasmas Genomes, Plant Hosts and Vectors. $C A B$ International, UK. Pp. 188-212

Doi, Y., Teranaka, M., Yora, K. and Asuyama, H. 1967. Mycoplasma- or PLT group-like microorganisms found in the phloem elements of plants infected with mulberry dwarf, potato witches' broom, aster yellows, or paulownia witches' broom. Ann. Phytopathol. Soc. Japan 33: 259-266.

Fletcher, J., Wayadande, A., Melche, R.U. and
Ye, F. 1998. The phytopathogenic mollicute-insect vector interface: a closer look. Phytopathology 88: 1351-1358.

Gomez, D.K.A. and Gemez, A.A. 1984. Statistical Procedures for Agricultural research, $2^{\text {nd }}$ edition John Wiley and Sons, New York, p. 653.

Hogenhout, S.A., Oshima, K.E., Ammar, D., Kakizawa, S., Kingdom, H.N. and Namba, S. 2008. Phytoplasmas: bacteria that manipulate plants and insects. Mol. Plant Pathol. 9: 403-423.

Jarausch, W., Lansac, M., Bliot, C. and Dosba, F. 1999. Phytoplasma transmission by in vitro graft inoculation as a basis for a preliminary screening method for resistance in fruit trees. Plant Pathol. 48: 283-287.

Jayashree, K., Pun, K.B. and Doraiswamy, S. 1999. Virus-vector relationships of yellow vein mosaic virus and whitefly (Bemisia tabaci) in pumpkin. Indian Phytopath. 52(1): 10-13.

Kamińska, M. and Korbin, M. 1999. Graft and dodder transmission of phytoplasma affecting lily to experimental hosts. Acta Physiol. Plant 21: 21-26.

Khan A.J., Botti S., Paltrinieri S., Al-Sobhi A.M., Bertaccini A.F. 2002 Phytoplasmas in alfalfa seedlings: infected or contaminated seedling? 14th International organization of Mycoplasmalogy Conference, Viena, Austria, p. 148

Kirkpatrick, B. C. 1991. Mycoplasma-like organisms-plant and invertebrate pathogens. In: Balows, A., Truper, H. G., Harder, W., and Schleifer, K.H. (eds.). The prokaryotes, 2nd Ed, New Yourk, Springer. pp. 4050-4067. 102

Kumar, P. and Mishra, U.S. 1992. Diseases of Sesamum indicum in Rohilkhand: Intensity and yield loss. Indian Phytopathol. 45: 121122.

Marcone, C., Ragozzino, A. and Seemüller, E. 1997. Dodder transmission of alder yellows phytoplasma to the experimental host Catharanthus roseus (periwinkle). European J. Forest Pathol. 27: 347-350.

Marzachì C., Milne R.G., Bosco D. 2004. Phytoplasma-plant-vector relationships. In: Pandalai, S.G. and Gayathri, A. (eds.) Recent Research Development in Plant 
Pathology, Vol. 3. Research Signpost, Trivandrum, Kerala, India, pp. 211-241

Nabi, S., Madhupriya, Dubey, D., Rao, G.P., Baranwal, V.K. and Sharma, P. 2015. Characterization of phytoplasmas associated with sesame (Sesamum indicum) phyllody disease in North India utilizing multilocus genes and RFLP analysis. Indian Phytopath. 68(1): 112-119.

Olivier C.Y., Séguin-Swartz G.,Hegedus D. 2006 First Report of "Candidatus Phytoplasma asteris" related strains in Brassica rapa in Saskatchewan, Canada. Plant Disease, 90: 832. 106

Pathak, D.M., Joshi, N.S., Dulawat, M.S. and Patel, N.V. 2013. Control of sesame phyllody caused by PLO's. Intern. J. Green Herbal Chem. 2: 164-165.

Pathak, D.M., Parakhia, A.M. and Akbari, L.F. 2012. Symptomatology and transmission of sesame phyllody disease caused by phytoplasma. J. Mycol. Plant Pathol. 42: 479-484.

Prasad, S. M. and Sahambi, H. S. 1982. Sesamum phyllody - some new host records. Ind. Phytopathol. 35(1): 159-160.

Rashid, M.H., Hossain, I., Alam, M.S., Zaman, M.M. and Hannan, A. 2008. Study on virus-vector relationship in TYLCV of tomato. Intern. J. Sustain. Crop Prod. 3(1): $1-6$.

Razin S., Yogev D., Naot Y. 1998. Molecular biology and pathology of mycoplasmas.
Microbiology and Molecular Biology Review, 62: 1094-1156

Sahambi, H.S. 1970. Studies on sesamum phyllody virus: virus-vector relationship and host range. In: Plant disease problems, Proc. The first international symposium plant pathology. IARI, New Delhi, India, pp. 340-351.

Salehi, M. and Izadpanah, K. 1992. Etiology and transmission of sesame phyllody in Iran. $J$. Phytopathol. 135: 37-47.

Salehi, M., Izadpanah, K., Siampour, M., Firouz, R. and Salehi, E. 2009. Molecular characterization and transmission of Safflower phyllody phytoplasma in Iran. $J$. Plant Pathol. 91(2): 453-458.

Shyu, Y.S.S. and Hwang, L.S. 2002. Antioxidant activity of white and black sesame seeds and their hull fractions. Food Res Inter. 35(4): 357-365.

Verma, O.P. and Daftari, L.N. 1976. Chemical control of bacterial leaf spot of sesamum in Rajasthan. India Phytopath. 29: 59-61.

Webb, D.R. 1999. Oligonucleotides as hybridization probes to localize phytoplasmas in host plants and insect vectors. Phytopathoogy. 89: 894-901.

Weintraub P.G., Beanland L. 2006. Insect vectors of phytoplasma. Annual Review of Entomologz, 51: 91-111.

\section{How to cite this article:}

Shankar Hemanta Gogoi, M.K. Kalita and Nath, P.D. 2017. Biological Characterization of Sesamum Phyllody Disease in Assam, India. Int.J.Curr.Microbiol.App.Sci. 6(11): 1862-1875. doi: https://doi.org/10.20546/ijcmas.2017.611.222 